\title{
Professional Identity via Virtual Corporate Discourse: Linguistic Perspective
}

\author{
Inna Poteryakhina*, and Alexander Bagiyan \\ Pyatigorsk State University, 357500 Pyatigorsk, Russia
}

\begin{abstract}
The article is devoted to the linguistic, social and psychological characteristics of the professional identity including its cognitive, behavioural and emotional components. The paper considers the role of virtual corporate discourse in the processes of formation, monitoring and developing of the professional identity. In authors' opinion, corporate discourse can be considered as the exponent of the intentions, knowledge and skills of communicants and their level of professionalism, so the elements of virtual corporate discourse differentiating specialists and laymen, as well as linguistic means preferred by both groups in their professional interaction, are analyzed in the work on the material of official corporate websites.
\end{abstract}

\section{Theoretical and methodological study of professional identity in humanitarian research}

The growing interest of researchers in various fields of humanitarian knowledge in the problem of professional identity is a reaction to changing social and economic conditions, new standards for the training of professionals and constantly growing demands for professionalism. Professional identity is studied by scientists such as M.M. Abdullaeva, E.P. Ermolaeva, D. Hughes, R. Iedema, J. Maybin, S.Neary, Yu.P. Povarenkov, L.B. Schneider, H. Scheeres, D.I. Zavalishena, and others, and refers to the number of concepts in which person's conceptual visualisation of his place in a professional group or community is expressed. This view is accompanied by certain value and motivational focus, as well as a subjective attitude toward one's professional affiliation. Following E.P. Yermolayeva, we believe that professional identity is the result of a long personal and professional development that develops only at high enough levels of mastering the profession and acts as a steady adjustment of the basic elements of the professional process, namely, the reconciliation of real and ideal professional images of personality (Ermolayeva, 2001). Deeper mastering of professional standards and stereotypes differentiates and organizes the image of the "ideal professional", which is complemented by the image of "representing oneself as a professional", which is more and more refined in the course of professional selfactualization - from stereotypes of behavior in unpredictable situations, self-realization and development of personality in the environment to mastering a special discourse, which suggests knowledge of potential scenarios and knowledge of terminology.
Otherwise, a person risks remaining at the level of performing a narrow set of functions, being unable to transform them taking into account changed circumstances. D.I. Zavalishena defines professional identity as the characteristic of a person who chooses and realizes the way of professional interaction with the outworld and acquires the sense of self-esteem through the performance of this activity. (Zavalishena, 2001). In addition, professional identity presupposes the understanding of their profession, acceptance of themselves in the profession, ability to perform their professional functions well and profitably for others. Professional self-determination as an integral part of professional identity is a long process of realization of intrapersonal and social-professional needs, the process of personal formation of one's attitude to the professional environment and the way of its self-realization.

It is important to study the mechanisms of building professional image standards. And here cultural and professional identities act as internal stabilizers of the system of ideas about themselves. Culture is emotionally perceived as a stable (having historical roots) whole, which provides a whole range of standards for identification (characters of art works, cultural figures), these very standards fill culture with personal content and attitude, linking personal and cultural identity. Professional identity can also become a link for different types of identity, contributing to the rootedness of a person in his profession, in society and in his ideas about himself.

In the structure of identity, the following components are distinguished: values, goals, beliefs; needs, abilities, beliefs, individual history. Identity as a process represents an ever-changing dynamic structure, the components of which change or are built into the structure through the mechanisms of differentiation and

Corresponding author: poteryakhinain@gmail.com 
integration, assimilation and accommodation. Sources of identity formation are the solution of the central problems of each stage of development, problem solving.

Active computerization, dissemination of mass media and communication have introduced a new component in the process of personality formation. The influence of the media on the process of personal development is one of the most important problems being developed by modern humanities.

Professional identity affects the level of professionalism, and therefore, the effectiveness of professional activity (R. Iedema, H. Scheeres, Yu.P. Povarenkov, L.B Schneider, etc.). Highly-qualified specialists have a higher motivation to achieve success in their professional activity than non-identical ones. Such specialists usually provide competent decisions in the organization.

It should be noted that a full and comprehensive linguistic-socio-psychological study of professional identity has not yet been conducted, which undoubtedly causes a number of contradictions, namely:

- between the needs of society in qualified specialists and the level of professional identity of graduates of educational institutions;

- between expectations of their profession and the level of its prestige;

- between expectations from their professional groups and the level of value-professional unity in them;

- between the degree of study of linguistic-sociopsychological characteristics of professional identity in various spheres and the growing need to raise the level of the most professional identity.

These contradictions entail the existence of another important problem, which consists in the insufficiently studied linguistic-socio-psychological characteristics of the professional identity of specialists in various spheres: power structures, health care, education and commercial organizations. It is proved that the higher the level of professional identity, the higher the career orientation of a specialist in professional competence, the higher his assessment of the professional competence of his colleagues. However, until now, all those factors, including linguistic ones, that affect the formation of professional identity have not been identified.

The foregoing explains the relevance of this study, the subject of which are the linguistic markers of professional identity in virtual corporate discourse.

According to the unanimous opinion of specialists, professional identity in various spheres can be successfully formed taking into account personal and organizational factors in the course of formation:

- cognitive component, which is social professional knowledge, a special picture of the world of ideas about the profession and about the professional group and about oneself as a professional;

- behavioral component, as professional motives, competencies and business communication scenarios.

- emotional component, which includes selfsatisfaction, profession, professional group, empathic contact and emotional regulation.
So, professional identity is a multidimensional, integrative (personality-group), socio-psychological phenomenon, representing the degree of identification of a person with a profession and including him in a professional group on the basis of social ideas and business communication, resulting in perception, as well as emotional the evaluation by different specialists of themselves, the characteristics of the profession and the group. In this case, various interaction effects arise, primarily manifested in the value-professional unity.

The level of professional identity as a result of its development consists of the values of the three components of the phenomenon being studied: cognitive, behavioral and emotional. The wider the views of specialists about themrselves, about the profession and about the group, the higher the emotional assessment of these representations, and also the more effective the interaction of an individual and the professional group and the higher the motivation for achieving, the higher the level of professional identity. The cognitive component of professional identity includes such variables as the content and scope of the conceptual structure, general knowledge, the general picture of the world, knowledge of behavior patterns, including communicative ones. The behavioral component includes the motivation to achieve success, the number of professional activities, the number of professional meetings of the professional group per year, the number of colleagues, the traditions of the professional group, the list of regulatory documents, models of communicative interaction of members of the professional group, the availability of the head of the professional group, communication (the presence of a specialized forum for a professional group, the implementation of business correspondence by e-mail, obtaining information about conferences, forums by email, communicative communication within corporate sites). The emotional component is represented by variables such as self-assessment, self-satisfaction as professional, satisfaction with the profession, a professional group, evaluation of the prestige of the profession, assessment of the level of awareness, interactivity and material-technical base of the professional group.

\section{Professional identity in virtual corporate discourse (VCD)}

As it was already mentioned, today the Internet space has a huge impact on the formation and development of the individual's identity, including the professional selfdetermination of each specialist, introducing a specific specificity into each of the above mentioned components of professional identity. Experts unanimously affirm the fact of virtualization of society. Today it is already obvious that the Internet is a virtual world in which virtual discourse rules. From the perspective of the sociolinguistic approach, it can be argued that virtual discourse is a linguistic category that combines the signs of a person-centered and status-oriented discourse, regardless of whether it is about chatting in web chats, 
blogging or thematic forums, webinars, network conferences. Virtual discourse is a complex communicative system, which, along with information and entertainment content includes virtual corporate discourse.

It should be noted that the Internet environment provides those opportunities that, on the one hand, are highly valued in business communications, on the other hand, could not be realized outside of electronic space. Today we can say that the Internet has not only an informative function but mostly a communicative one. This particular, virtual, type of communication lies outside the temporal and spatial framework and is a reflection of real objects, actions, relationships and institutional forms.

The main quantitative characteristic of the addressee of the VCD is its mass character; its qualitative feature is expressed by its sociality, which is conditioned by business relations and certain social roles (Shiryaeva, 2014).

The basic goals of virtual corporate discourse are:

- ensuring the professional interaction of a wide range of stakeholders,

- consolidation and preservation of a corporate institution (or a separate corporation) in a discursive system;

- the most positive representation of the organization's image in the virtual space, by ensuring a positive attitude towards the company from significant target audiences, regardless of their remoteness.

Taking into account the vision of E.V. Gryaznova of virtual communication as the unity of the four processes, it consist in the creation of a new reality, the reflection of objective reality, the expression of the subjectivepersonal world and the transfer of its spiritual content to all participants (Gryaznova, 2001), We propose to consider virtual corporate discourse as a space for the realization of the following processes: the re-creation of professional identity in a new space; reflection of significant results of activities of participants in the professional community; the expression of the professional picture of the world; translation of corporate values, rules, priority activities. Undoubtedly, today the study of the processes mentioned above, the analysis of the patterns of their implementation and factors of the formation and / or diagnosis of professional identity through virtual corporate discourse is of considerable interest both for practitioners and for various researchers.

Communication participants are users of corporate information resources provided by the global Internet network or internal corporate LAN. The addressee of the virtual corporate discourse can be an individual who acts as the initiator of the communicative interaction of a professional group, or a company that forms a kind of virtual "replica", for example, in the form of a corporate website. It should be noted that the addressee of VCD represents a certain generalized person, uniting both the company's management and its employees.

The addressees of the VCD can be a wide range of persons interested in professional interaction, among which there are several status and role groups: potential partners, investors, controlling bodies, employees and, finally, consumers of goods and services of the company. The peculiarity of the VCD recipients is their relative activity in the formation of the content of this discourse, the ability to change their role under certain conditions and act as an addressee, which becomes possible due to hypertext, when the user, regardless the linearity of the text, individually determines the nature and volume of the received content.

Proceeding from the foregoing, it should be noted the obvious importance and relevance of the research of virtual corporate discourse as a means of diagnosing and monitoring the formation and development of professional identity.

\section{Practical diagnostics of professional identity on corporate websites}

One of the genres of virtual corporate discourse is a corporate website. Linguistic research of a corporate site as a multifunctional space is relevant due to the fact that currently the global positioning of an organization, enterprise or firm takes place through virtual representation on the Internet: informing the public in the worldwide network by providing relevant, reliable and complete information through establishing and maintaining an effective communication, as well as through feedback and public opinion polls.

The corporate website is a relatively stable and reliable source of information about the organization, both for the internal corporate community (company personnel, heads of structural units, shareholders directly and permanently involved in the management of the company) and for the external audience (suppliers of raw materials, materials and components, consumers of products, state control and regulation bodies, etc.); so it involves communication as a specialist, and an amateur (unprepared, but motivated to obtain special knowledge recipient).

The publication of information on its official website allows the corporation to notify its potential customers about the range of products and services offered, to inform the public about significant events in the life of the organization, for example, mastering the production of a new product line or applying innovative technologies, changes in the formation of the company's pricing policy or seasonal shares; maintain a favorable image of the company and its products, which in turn will promote the loyalty of customers, investors and partners. The global Internet network is a combination of various multimedia opportunities for radio and telecommunications impact on the audience, which is undoubtedly very important, as the potential audience of Internet users is constantly growing.

The modern corporate website, as a rule, performs not only an informative function, but also a management one, helping to solve a whole complex of tasks to implement effective interaction in a single space between representatives of the company's branches, conduct various kinds of settlements, and provide internal access to manage corporate databases. 
Despite the seeming neutral style of the corporate site texts, due to the orientation of the sites to the widest audience, the linguistic analysis of the sites being researched clearly demonstrates a large number of elements differentiating specialists and laymen.

So, the following text is addressed to specialists who clearly understand what is behind the names of technologies, because only in this case we can judge the reliability of the described technology "Hybrid Cloud Solutions": "Lastly, in terms of platform reliability, availability, and serviceability (RAS) features, the new Intel Xeon Scalable processors inherit all the RAS features, including Intel ${ }^{\circledR}$ Run Sure technology from the latest-generation, mission-critical Intel Xeon processor E7 family, but with their own additions. Intel $₫$ Run Sure technologies. These, combined with $70+$ proven RAS features, provide IT with additional peace of mind for the hybrid cloud infrastructure". In turn, the following passage of the VCD is intended only to attract attention and does not require special knowledge: "Modern and Efficient. Today, more than two thirds of enterprises prefer a hybrid cloud approach for improved operations and greater productivity. Support business growth with new benefits from broad choices and capabilities for hybrid cloud deployment of applications and emerging workloads. In this example, using contrast and references to the majority, the addressee presents the advantages of using the new technology, understandable to any recipient, which does not require additional knowledge from him.

Language tools used by participants in communication to implement their own communication goals are considered superficial, visible text textures. They are obvious, they can testify about the purposes and intentions of communicants, their diagnosis allows to give information about the installations, strategic plans and tactical tasks of communicants.

For example, an appeal to potential partners on the Intel website: "Intel partner programs provide members with exclusive content and resources to get more out of Intel ${ }^{\circledR}$-based solutions.

Partnership with Intel provides you with a range of benefits, including partner-only training and events, access to roadmaps and resources, co-selling opportunities and more

Demonstrate your affiliation with Intel and use it to differentiate yourself in a crowded marketplace. " Here, Intel predicts success with "exclusive content and resources", undoubtedly, any partnership assumes mutual benefit and in this example "benefits" are listed. In addition, the partnership ("affiliation") with Intel will allow the partner company to stand out in the market, as is unequivocally stated in this passage.

It should be noted who the coding and interpretation of the text is based on the previously obtained cognitive knowledge of participants in professional interaction when applying this knowledge directly to the act of communication. The communicative effect of the operations performed by the participants of the interaction testifies to the correctness or incorrectness, expediency or inexpediency of the selected means and methods of encoding and decoding the text. Thus, an important condition for successful communication and the mark of belonging to the professional circle is the choice of language means by which the speaker expresses his understanding of the situation and attitude to it.

Only an expert, a person who is competent in technologies can fully understand and evaluate the idea behind the following information published on the official website: "The performance begins with Intel's powerful 45W mobile processor, delievering four cores and eight threads on each processor. This enthusiast processor is then connected to a custom discrete Randeon RX Vega M graphics processor via Intel's high speed PCIe* lanes directly connected to processor. This enables the bandwidth needed for the CPU to feed the graphics compute units (up to 24 Compute units) to run up to $1190 \mathrm{MHz}$ boost frequency." As the given example demonstrates, the choice of the vocabulary to describe new achievements and inventions when the audience is supposed to be experts is represented by terms, names of technologies and abbreviations which makes the text really vague for the amateurs. Both the author and the adressee identify themselves with a certain professional circle, with particular knowledge, language, professional affiliation.

In the following text, after a series of technical instructions for Intel software users, one of the answers contains explanations not of a technical nature, explaining to the user the need for updates: "Trust me, It is a simple thing to blame someone else. I just wanted to prove a point. If we did not provide the information, we would be unable to provide you with any information. This is what we call Progression. " And this text clearly says that the recipient does not belong to the professional circle.

The discrepancies between the speech impact and response to it, which arise as a result of inappropriate speech behavior of one of the communicants within the given scenario or the social communicative role chosen by them, often manifests itself in a deviation from traditional speech strategies and tactics in a communicative act.

For example, at the forum "Intel ${ }^{\circ}$ RealSense Community" after a series of unsuccessful attempts to update, users move from technical messages to emotional comments: "Intel: this is totally unprofessional what are you with your own products!!!!", "Still nothing? INTEL: WAKE UP!!!!!!!!"and "The great announcement is that they obviously "go back (from where?) To the latest drivers that DO. NOT. WORK!

Sorry, but that is simply not acceptable. Go and FIX that.

NONE of the workarounds work. I tried all of them, and I tried them more than once or twice. HOURS of WORK into this and its just not working.

I want the FIXED driver to be supported by me".

In these comments, accentuation of the text by punctuation marks and capital letters is noticeable, which is traditionally considered to be the equivalent of increased tone in Internet communication, as well as the use of expressive vocabulary. 
Thus, professional identity is formed by holistic standards of typical professional events and conceptual schemes of professional interaction, including communicative behavior. Virtual corporate discourse is a modern platform for both diagnosis and the formation of professional identity. Investigations of virtual corporate discourse, in particular, corporate websites of various professional spheres as a means of honing professionally important qualities, self-development of a professional and determining belonging to a certain business environment, are promising and are the source of fundamental knowledge for the linguistic projection of professional identity. In the authors' opinion, the study of these issues contributes to the development of the conception of professional identity and its peculiarities from linguistic point of view.

This study was supported by the grant from the Council for grants of the President of the Russian Federation [project "Conceptual linguistic engineering of professional identity in innovative economy: linguo-cognitive, socio-lexicographic and pragma-axiological modeling of Russian and Western European popular scientific discourse" grant No MK6895.2018.6].

\section{References}

1. M.M. Abdullaeva, Psychological journal 25(2), 8695 (2004)

2. E.P. Ermolayeva, Psychological journal 22(4), 51$59(2001)$

3. D. Hughes, British Journal of Guidance and Counselling 41(1), 58-68 (2013)

4. R. Iedema, H. Scheeres, Applied Linguistics 24(3), (2003) 316-337

5. J. Maybin K. Richards, Applied Linguistics 29(1), 164-167 (2008)

6. S. Neary, Career Matters 2 (3), 14-15 (2014)

7. S. Neary, British Journal of Guidance and Counselling 42(2), 199-210 (2014)

8. Yu.P. Povarenkov, Siberian journal of psychology 24, 53-58 (2006)

9. L.B. Shneider, Professional identity: theory, experiment, training (Voronezh,"MODEK", 2004)

10. D.N. Zavalishena, Methods of identification of a person with a profession (M., Yaroslavl, 2001)

11. T.A. Shiryaeva, The structural-content and functional paradigm of modern business discourse: diss. ... Doct. philol. sciences, (Nalchik, 2014)

12. E.V. Gryaznova, Computer Communication as a Social Phenomenon: Thesis ... Candidate of Philosophical Sciences, (Nizhny Novgorod, 2001) 